\title{
Structural Changes of Hematite Grains Composing a Self-fluxing Pellet during Hydrogen Reduction*
}

\section{By Shigeji TANIGUCHI, ${ }^{* *}$ Munekazu OHMI** and Hitoshi HUKUHARA ${ }^{* * *}$}

\section{Synopsis}

Structural changes appearing during hydrogen reduction of hematite grains composing a self-fluxing pellet have been studied for specimens partially reduced at temperatures between $700^{\circ}$ and $1000^{\circ} \mathrm{C}$.

The reduced magnetite structure depended to a large extent upon the reduction temperature and its variation was confirmed to be similar to that observed by other workers.

However, it was very difficult to find any sign of the mechanical failure of reported types during the reduction of hematite to magnetite.

Wustite phase nucleated preferentially on surfaces of micropores inside of a magnetite grain during the initial period of its reduction. Its periphery remained almost free of wustite until the final stage of the conversion of magnetite to wustite.

Iron nucleation again took place preferentially inside of the wustite grain at lower temperatures. At $1000^{\circ} \mathrm{C}$ iron nucleated at corners of disintegrated wustite particles and the complete coverage of its surface with iron took place after considerable volume of the grain was converted.

The topochemical manner was unlikely for the three reduction steps at any temperature except the very final stage of the conversion.

The nature of micropores was also studied. Massive magnetite contained micropores radiating toward the hematite/magnetite interface, while the needle magnetite was free of these micropores indicating high perfection. The directional nature of micropores formed in the iron grain at intermediate temperatures seemed to be inherited from the anisotropic nature of the original hematite.

The above observations were common for five other self-fluxing pellets produced in a similar way, of which basicities are different from 0.64 to 2.54 and slag contents from 7.3 to $16.3 \%$.

\section{Introduction}

The overall rate of the reduction of various hematite pellets has been studied by many workers, ${ }^{1-5)}$ who have considered that the reduction step of wustite to iron was mainly responsible for the rate. Then, the reduction steps to wustite have often been overlooked. However, the reduction of a hematite pellet proceeds with the intermediate formation of lower oxides, the physical nature of which is dependent upon the reducing conditions ${ }^{6)}$ and thus influences the subsequent reduction rate.

On the other hand, some mathematical models ${ }^{7,8)}$ for describing the reduction processes have been developed with an assumption that the oxide grains composing a pellet were reduced in a topochemical manner.

Recent structural studies ${ }^{9-12)}$ have, however, shown that there are cases where the topochemical manner is unlikely. Even advanced mathematical models ${ }^{13,14)}$ which included the three successive reduction steps neglected structural factors.
Considering the above situation, detailed structural studies are requested not only for establishing more reasonable mathematical models suitable for the individual purposes taking account of structural factors but also for understanding the process of mechanical failure of pellets during reduction as well as swelling phenomenon.

Therefore, growth morphologies of various phases which appear during the reduction of hematite grains composing a pellet and the associated variation of physical nature of the grains were studied in the present work to some detail.

\section{Experimental Procedure}

A series of metallographic examinations was carried out for partially reduced pellets including six kinds of self-fluxing laboratory pellets made from high grade hematite ore with suitable additions of $\mathrm{CaO}$ and $\mathrm{SiO}_{2}$ so as to have basicity ranging from 0.64 to 2.54 and slag content from 7.3 to $16.3 \%$. As they showed similar tendencies in morphology change during reduction, the present work deals mainly with the result of one of them extensively studied.

The compositions and other properties of the pellet have been reported elsewhere. ${ }^{15)}$ Partially reduced pellets of aimed degrees of reduction, 20, 50 and $80 \%$, were obtained after hydrogen reduction for suitable periods determined by a preliminary experiment. The reducing gas composition was $50 \% \mathrm{H}_{2}-50 \% \mathrm{~N}_{2}$ and its flow rate $4 \mathrm{~N} / / \mathrm{min}$. The isothermal reduction temperature ranged from $700^{\circ}$ to $1000^{\circ} \mathrm{C}$. After the reduction the pellets were set in mounting plastic, cut and polished on a series of successively finer silicon carbide papers. Then, the final polishing was carried out on a vibration polisher with 6,1 and $1 / 4 \mu \mathrm{m}$ diamond paste used in this order.

Hematite, magnetite and iron were readily identified in the polished section, since they have different reflectivities. However, magnetite and wustite were distinguished after chemical etching with an ethanol solution saturated with stannous chloride, because the solution attacks wustite ${ }^{16)}$ only. Aqua regia was also used for etching magnetite phase. ${ }^{16)}$

Although the pellet contained slag phases and other oxides, the reduction sequences of hematite grains were attentioned.

Further details of the experimental procedures including the apparatus have been reported previous-

* Partly presented at the 95th ISIJ Meeting, April 1978, at The University of Tokyo, Tokyo 113. Manuscript received September 10, 1979.

** Department of Metallurgical Engineering, Faculty of Engineering, Osaka University, Suita, Osaka 565.

*** Formerly Graduate School, Osaka University. Now at Shin-Nihon Koki, Ltd., Sakai, Osaka 590. 
ly. ${ }^{15)}$

\section{Results}

\section{Hematite to Magnetite Step}

The growth morphology of magnetite in a hematite grain during its conversion appeared to be dependent to a large extent upon the reduction temperature as shown in Photo. 1.

At the lowest temperature of $700^{\circ} \mathrm{C}$ massive magnetite crystals grew into a hematite grain radially from their nucleation sites on the hematite surface, Photo. 1(a).

The number of this nucleation site was usually quite small. The hematite/magnetite interface propagated keeping a nearly hemispherical shape during the magnetite growth until it met another interface. The magnetite grew in the similar manner at $800^{\circ} \mathrm{C}$ as shown in Photo. 1(b), but the interface became slightly rugged. Massive magnetite associated with a group of magnetite needles was also observed, though its number was small.

It is noteworthy that a considerable amount of volume was converted into magnetite before the whole surface of the original hematite grain was covered with magnetite. Therefore, it may be said that the reduction does not proceed in the topochemical manner.

Further increase in the reduction temperature resulted in a particular magnetite shape, a needle, as shown in Photo. 1(c). The needle crystals tended to grow along a single direction in a hematite grain leaving themselves almost parallel each other. This directional growth was maintained even in hematite twin crystals.

The growth of needle magnetite appeared to be limited and further conversion of the remaining hematite was performed by the propagation of massive magnetite.

At the highest temperature of $1000^{\circ} \mathrm{C}$ the massive magnetite predominated again; however, it was almost always preceded by a few needle crystals as shown in Photo. 1(d).

The nature of micropores formed in a magnetite phase was closely examined. The massive magnetite formed at any temperature contained micropores. Directional nature of slightly elongated micropores was recognizable in some grains as shown in Photo. 2. The size of these micropores tended to become finner toward the hematite/magnetite interface and they disappeared or became unrecognizably small in the close vicinity of the interface.

On the other hand, the needle magnetite appeared to be free of micropore, though the massive magnetite present around the needles contained many.

An etching treatment with aqua regia revealed that the massive magnetite had a substructure more or less at any temperature, Photo. 3, though it appeared to be uniform under an optical microscope after ordinary polishing. The needle magnetite seems to have higher perfection than the massive magnetite judging from
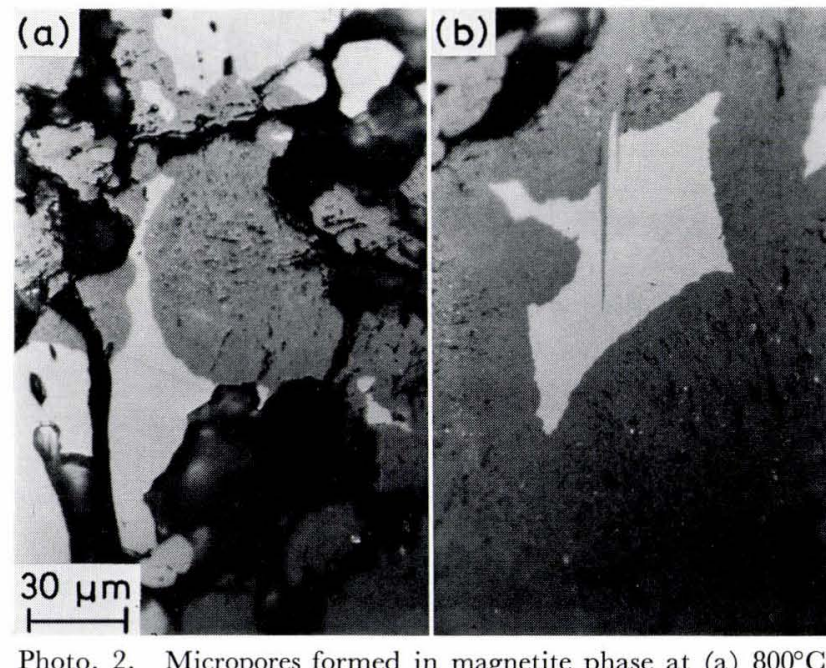

Photo. 2. Micropores formed in magnetite phase at (a) $800^{\circ} \mathrm{C}$ and (b) $1000^{\circ} \mathrm{C}$.

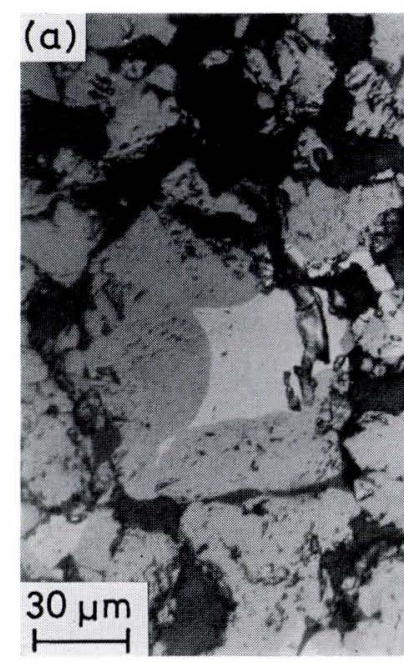

White: hematite

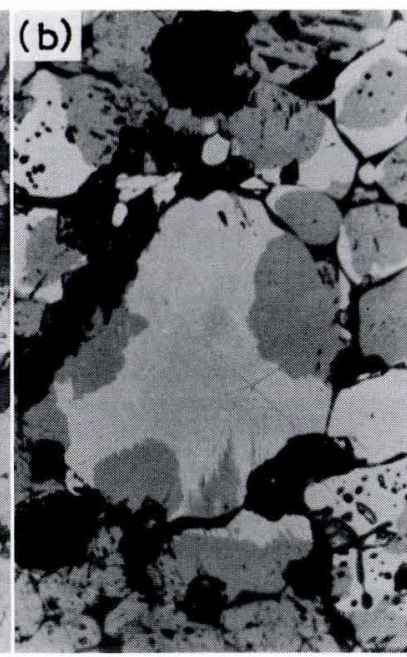

Gray: magnetite

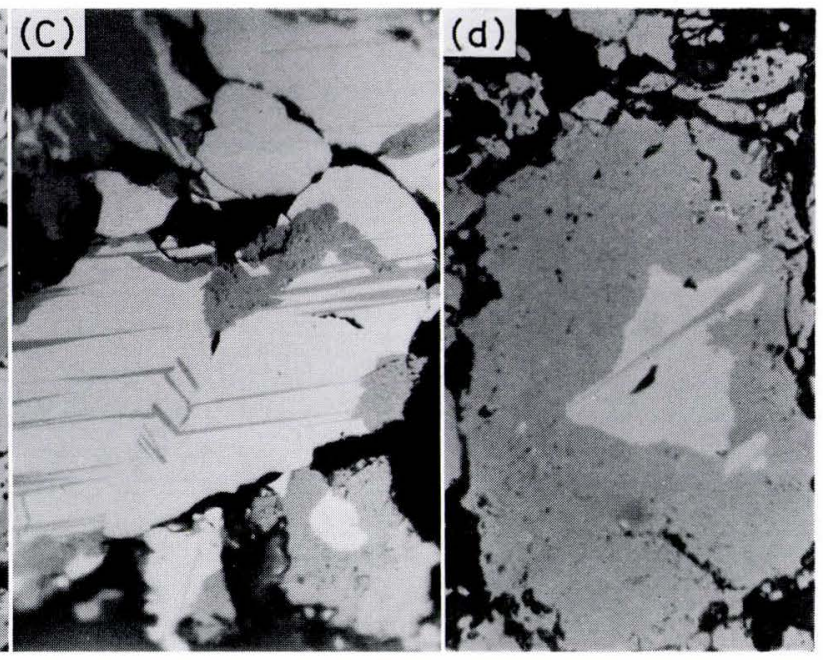

Dark: pore

Photo. 1. Various features of magnetite phases growing in hematite grains, reduced by $20 \%$ at (a) $700{ }^{\circ} \mathrm{C}$, (b) $800^{\circ} \mathrm{C}$, (c) $900^{\circ} \mathrm{C}$ and (d) $1000^{\circ} \mathrm{C}$. 
different degrees of etch.

\section{Magnetite to Wustite Step}

The wustite phase formed in the magnetite grain, which had been converted from hematite, was identified by the etching treatment with the stannous chloride solution. The wustite phase grew preferentially on surfaces of micropores inside of the magnetite grain at any temperature, as shown in Photo. 4. At $1000^{\circ} \mathrm{C}$ the wustite appeared in a bulky form along relatively large micropores, or fissures, in the magnetite grain.

From the distribution of the wustite phase the nature of micropores can be understood. At $700^{\circ} \mathrm{C}$ the wustite distributed keeping a slight directionality as shown in Photo. 4(a). Periphery of each magnetite grain was almost free of wustite until the final stage of its conversion.

As the temperature rose, the directionality of wustite distribution, or of micropores, became clearer as shown in Photos. 4(b) and (c). Only a single

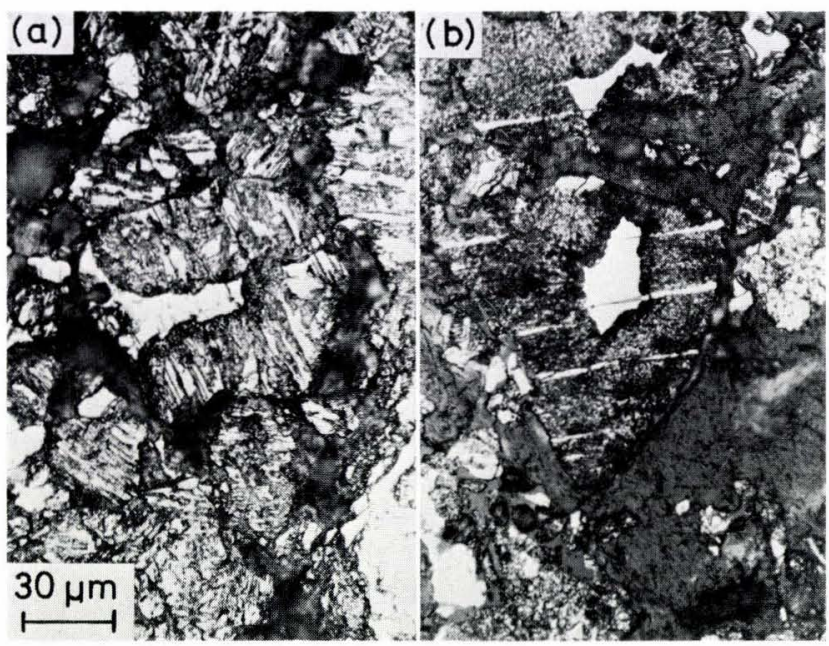

Photo. 3. Substructures in magnetite phases formed at (a) $800^{\circ} \mathrm{C}$ and (b) $1000^{\circ} \mathrm{C}$. Etched with aqua regia. direction predominated in a small grain, while relatively large grains had colonies where different directionalities were present.

\section{Wustite to Iron Step}

At the lower temperatures most wustite grains maintained the size almost equal to the original hematite, though many micropores were formed in them as shown in Photos. 5(a) and (b). Their outer surfaces were fairly sound leaving these micropores inaccessible for the reducing gas.

Iron nucleated on surfaces of these micropores in preference to the outer surface of the grain.

Relatively large grains contained elongated micropores aligned along a single direction at $900^{\circ} \mathrm{C}$ as shown in Photo. 5(c). Some large grains disintegrated into smaller particles in which this kind of micropore was rare. The iron nucleation took place on inner surfaces as well as on outer surfaces simultaneously indicating that these micropores were accessible for the reducing gas. Then, thin iron layer covered the particles soon.

Further increase in the temperature resulted in extensive disintegration of the wustite grains.

The preferential iron nucleation started at the limited corners of wustite particles, Photo. 5(d). Considerable volume of wustite was converted into iron before the whole surface was covered with the iron layer.

From these observations it may be said that a topochemical manner is hardly feasible for the major part of the reduction step.

\section{Discussion}

\section{Hematite to Magnetite Step}

Different terminologies have been used by various workers for describing the morphology of the magnetite growing in a hematite grain, though it seems that they show virtually the same phenomenon. In the present study the words " massive" and " needle"
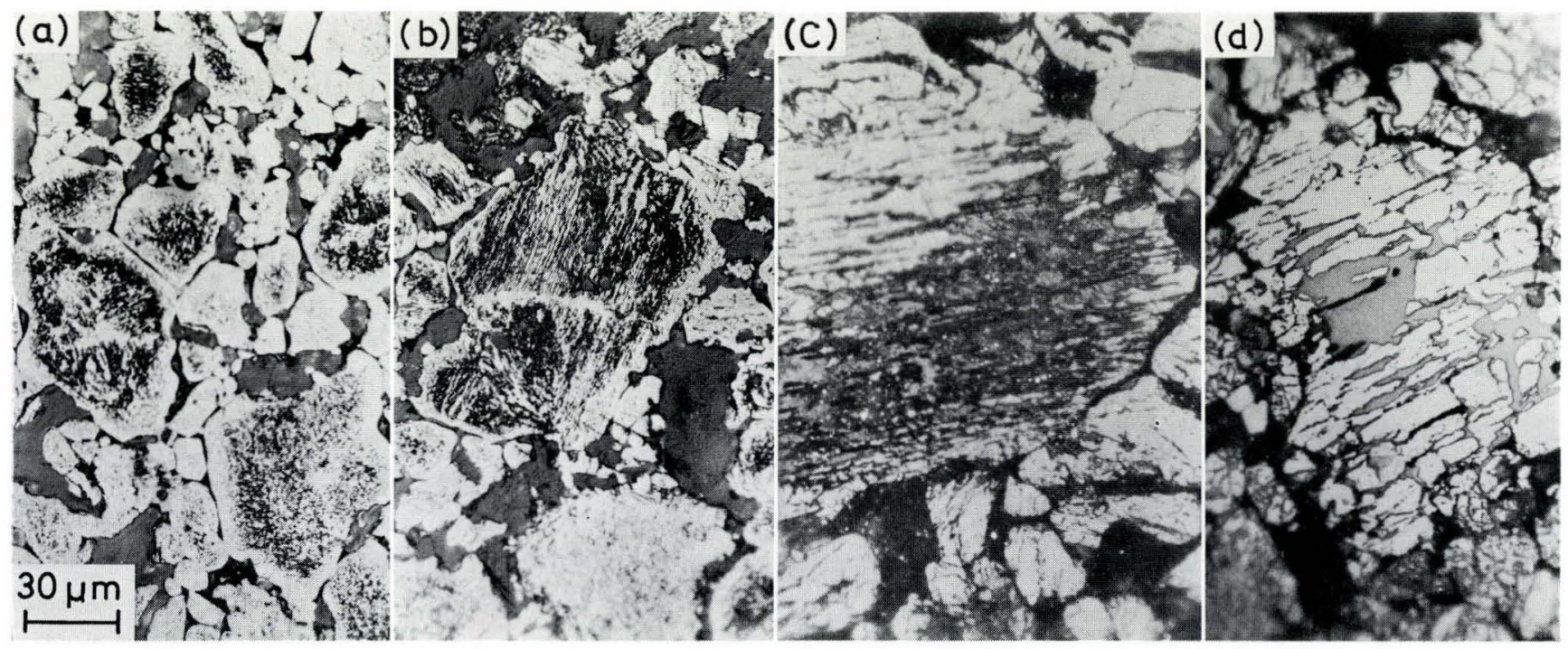

Photo. 4. Various features of wustite phases formed in magnetite grains at (a) $700^{\circ} \mathrm{C}$, (b) $800^{\circ} \mathrm{C}$, (c) $900^{\circ} \mathrm{C}$ and (d) $1000^{\circ} \mathrm{C}$. Etched with the stannous chloride solution. 

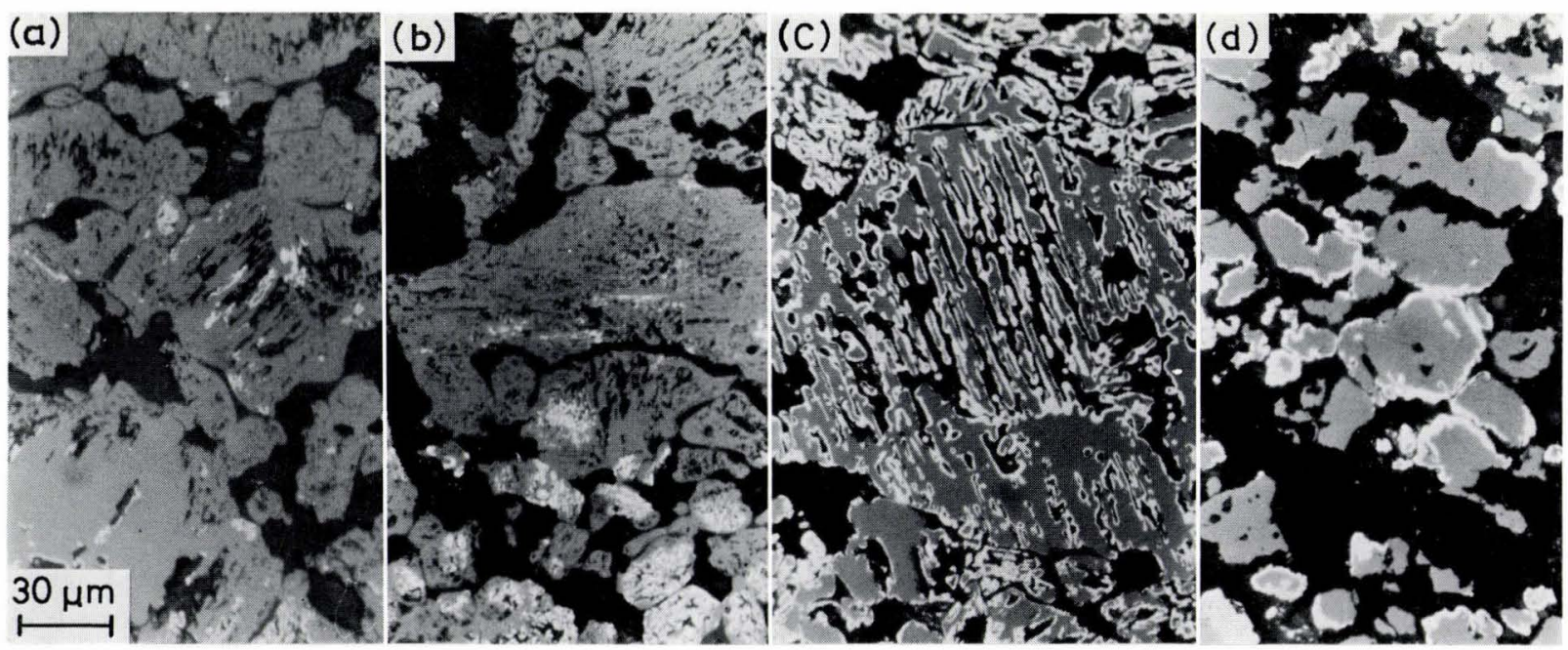

Photo. 5. Various features of iron nucleated in wustite grains at (a) $700^{\circ} \mathrm{C}$, (b) $800^{\circ} \mathrm{C}$, (c) $900^{\circ} \mathrm{C}$ and (d) $1000^{\circ} \mathrm{C}$.

were used for possibly equivalent "cellular"11) or colony ${ }^{12)} "$ and "elliptically conical, ${ }^{9)}$ banded, ${ }^{10)}$ lamellar $^{17)}$ or wedge-shaped ${ }^{18)}$ " respectively.

The result of the present study revealed that the morphological change of magnetite in a hematite grain was characterized to a large extent by the reduction temperature. This agrees roughly with other workers'9,11,12) recently reported, though there is a slight variation in the temperature range where a particular shape appears. For example, Brill-Edwards $e t a l{ }^{9)}$ reported that the lowest temperature at which a magnetite needle appears was $600^{\circ} \mathrm{C}$ and Swann and Tighe ${ }^{11)} 650^{\circ} \mathrm{C}$, while the present study $800^{\circ} \mathrm{C}$.

This difference may be attributed to the variation in the specimen nature and reducing conditions.

The radial growth of the magnetite may indicate that the mobility of the hematite/magnetite interface at these temperatures is isotropic, while the needle magnetite grows preferentially ${ }^{19)}$ in a particular direction.

Swann and Tighe ${ }^{11}$ ) found that the massive magnetite contained a system of thin tunnels radiating toward the hematite/magnetite interface using a high voltage electron microscope. The growth of the magnetite was maintained by the transport of the reactant and product gases through the tunnels. They suggested the following mechanism that the reduction took place at the bottom of the tunnel where hematite is exposed to the reducing gas and the excess iron ions formed diffuse laterally along the hematite/magnetite interface between the tunnels. They subsequently form magnetite with hematite, thus further development of the interface continues repeating these processes.

It was impossible to directly confirm the presence of the tunnels under the present optical microscope, since the diameter of the tunnel was of the order of several nano meter. ${ }^{11)}$

However, the directionality of the micropores in the close vicinity of the hematite/magnetite interface allows the application of the above mechanism to the present study. The radial distribution of micropores in the massive magnetite may be originated from the tunnel system, since the coalescence of the tunnels to become larger micropores is feasible during their subsequent anneal. A similar mechanism seems to apply for the growth of the massive magnetite at $1000^{\circ} \mathrm{C}$, since the nature of the micropores are almost same as those observed at the lower temperatures, Photo. 2.

The growth of needle magnetite, on the other hand, may involve solid state diffusion judging from its higher perfection. The diffusion along the hematite/magnetite interface is most likely.

However, favorable situations for this growth may be consumed very soon as the limited amount of the needle magnetite implies. Its sidewise growth is unlikely either, since its width was also limited.

The appearance of the above two types of magnetite may be a general sequence except the case at $1000^{\circ} \mathrm{C}$ where the massive magnetite predominated again, since the both types were observed during the reduction of hematite grains, composing agglomerates, of various origins such as reagent hematite, ${ }^{10)}$ natural ores $^{9,11,12)}$ and magnetite concentrates. ${ }^{6,17)}$

The different morphologies of the magnetite would result in a complicated temperature dependence of its intrinsic rate constant, since gaseous diffusion is usually much faster than solid state diffusion. In fact, a rate anomary was observed. ${ }^{18)}$ However, a simple temperature dependence was also reported ${ }^{14)}$ over the temperature range of consideration.

It was quite difficult to find any sign of mechanical failure of reported kind $^{9,20)}$ in magnetite formed or in hematite being converted. For example, though it was reported $^{9)}$ that cracks developed when two growing massive magnetite crystals met in a hematite grain, there was no indication of failure of this kind as shown in Photos. 1(a) and (d). Grains completely converted into magnetite were confirmed to be fairly sound. Bleifuss ${ }^{20}$ also observed cracks which were aligned toward the hematite/magnetite interface in the magnetite shell formed.

Another kind of failure was also reported ${ }^{9)}$ such that the hematite present between magnetite needles failed by the stresses, which were developed by the needle 
growth, exerted upon it. However, this did not take place in the present study as shown in Photo. 1(c).

The orientation relationship between the needle magnetite and the hematite matrix seems to be well established ${ }^{11,19-21)}$ such that the needle grows along the basal plane of hematite keeping the relationship (111) of magnetite//(0001) of hematite at the temperatures of consideration.

On the other hand, Bleifuss ${ }^{20)}$ observed that there was a dilation in a direction normal to the basal plane of hematite and a contraction parallel to this plane.

Following the above two facts, the hematite between magnetite needles is put in compression, while the magnetite in tension, along this interface. The lattice parameter data obtained by Baro et al. ${ }^{22)}$ also support this stress system acting at the interface.

Under this stress system the magnetite should fail before the hematite because of their different strengths unless any stress relief mechanism is operating.

However, the magnetite needles observed in the study were fairly sound as well as the hematite between them.

This requires a detailed study further for better understanding.

Even though the magnetite grains were fairly sound, the pellet swelled ${ }^{15}$ ) to some extent being associated with the formation of a few cracks. The swelling resulted in partial breakage of the bonding between the grains composing the pellet.

The mechanism shown by Bleifuss ${ }^{20)}$ is applicable for the observed swelling and the explanation has been given previously. ${ }^{15)}$

\section{Magnetite to Wustite Step}

It is surprising to note that wustite phase appeared first on the surfaces of micropores inside of the magnetite grain rather than on its outer surface. A possible mechanism is that the micropores provided favorable sites for the wustite nucleation. Solid state diffusion of iron ions through the magnetite may be responsible for the nucleation which is faster than the establishment of the area supersaturated with iron high enough to allow wustite nucleation on the outer surface.

A similar preferential diffusion to a particular site was observed for gas-solid reactions. ${ }^{23)}$

It was difficult to compare the above observation with other's, since the available work which included the structural factor of this respect was quite few. Urlich et al. ${ }^{24)}$ reported that the wustite layer was formed around the dense magnetite core during magnetite to wustite reaction. However, their specimen was dense and stabilized at the test temperature prior to the reduction.

Contrary to this, the magnetite converted from hematite at the lower temperatures in the present study was not stabilized and thus contain excess vacancies due to the mismatch in lattice parameters ${ }^{22)}$ of the both phases. These vacancies inside of the magnetite grain can be absorbed by the neighboring micropores, while these vacancies and micropores near the outer surface can escape out, resulting in the formation of the rim free of the preferential site for the wustite nucleation during subsequent reduction, Photo. 4(a). As temperature rises, this possibility increases. Especially at the higher temperatures recrystallization of the magnetite is possible leading to the rearrangement of the micropores or extinction of lattice defects.

The growth of wustite at the micropore may enlarge its size, since a considerable decrease in specific volume $^{25)}$ takes place enhancing the disintegration of the grain.

It is again interesting to note that at $800^{\circ} \mathrm{C}$ micropores are aligned in a direction in many grains, Photo. 4 (b), inspite of the growth of massive magnetite, Photo. 1(b).

The presence of the substructure together with the above facts suggests the occurrence of the rearrangement of the magnetite associated with the directional nature inherited from the original hematite. Similar process may take place at higher temperatures.

\section{Wustite to Iron Step}

The reduction step from wustite to iron has also been studied ${ }^{26-29 j}$ often with dense wustite specimens which were stabilized previously at each test temperature. The nucleation and the subsequent growth of iron observed to take place on the wustite surface. After the complete coverage of the surface with thin iron layer the reduction proceeded by the diffusion of oxygen $^{26,27)}$ through the iron layer in a topochemical manner.

The present result is, however, a variation especially at lower temperatures in respect to the iron nucleation which started inside of the wustite grain.

The mechanism involved is similar to that for the wustite nucleation in the magnetite grain shown above. This tendency decreased with the rising temperature, since micropores and lattice defects decrease with it.

\section{Summary}

The results of the present study on six kinds of self-fluxing pellets of various basicities and slag contents revealed the following points.

Complicated sequences take place during the reduction of hematite grains composing the pellets at temperatures between $700^{\circ}$ and $1000^{\circ} \mathrm{C}$.

During the reduction step from hematite to magnetite the mechanical failure of reported kinds were rarely seen and the grains converted fully into magnetite were fairly sound.

Two types of magnetite morphologies were observed. Massive magnetite contains a system of micropores aligned toward the hematite/magnetite interface, while needle magnetite seems to be almost free of defects.

The nucleation of wustite or iron started inside of the magnetite or the wustite grains respectively rather than on their outer surfaces. Thus, the topochemical manner was not feasible for the three reduction steps for the grain composing the pellet. 


\section{Acknowledgements}

The authors wish to thank Kobe Steel, Ltd. for the supply of the pellets.

\section{REFERENCES}

1) W. M. McKewan: Trans. AIME, 218 (1960), 2.

2) R.H. Spitzer, F.S. Manning and W. O. Philbrook: Trans. AIME, 236 (1966), 726.

3) Y. Hara, M. Tsuchiya and S. Kondo: Trans. ISIJ, 12 (1972), 223.

4) R. Takahashi, J. Yagi and Y. Omori: Tetsu-to-Hagané, 57 (1971), 1597.

5) J. Yagi, R. Takahashi and Y. Omori: Tetsu-to-Hagané, 57 (1971), 1453.

6) R. D. Walker, N. S. Ford and D. L. Carpenter: Proc. ICSTIS, I, Supple. Trans. ISIJ, 11 (1971), 473.

7) J. Szekely and J. W. Evans: Met. Trans., 2 (1971), 1691.

8) Y. Hara: Trans. ISIJ, 12 (1972), 358.

9) H. Brill-Edwards, B. L. Daniel and R. L. Samuel: JISI, 203 (1965), 361.

10) I. M. Morsi and H. U. Ross: Can. Met. Quart., 15 (1976), 139.

11) P. R. Swann and N.J. Tighe: Met. Trans., 8B (1977), 479.

12) J. R. Porter and P. R. Swann: Ironmaking Steelmaking, 4 (1977), 300.

13) R. H. Spitzer, F. S. Manning and W. O. Philbrook: Trans. AIME, 236 (1966), 1715.
14) T. Murayama, Y. Ono and Y. Kawai: Trans. ISIJ, 18 (1978), 579.

15) S. Taniguchi, M. Ohmi and H. Hukuhara: Trans. ISIJ, 18 (1978), 633.

16) The 54th Committee Japan Soc. Prom. Sci.: Trans. ISIJ, 7 (1967), 126

17) R. D. Walker and D. L. Carpenter: JISI, 208 (1970), 67.

18) A. V. Bradshaw and A. G. Matyas: Met. Trans., 7B (1976), 81 .

19) K. Meyer, H. Rausch and M. Ottow: Stahl u. Eisen, 87 (1967), 654 .

20) R. L. Bleifuss: Proc. ICSTIS, I, Suppl. Trans. ISIJ, 11 (1971), 52

21) M. Blackman and G. Kaye: Proc. Phys. Soc., 75 (1960), 364.

22) R. Baro, H. Moineau and J. J. Heizmann: Advances in X-ray Analysis, 11 (1968), 473.

23) C. Wagner: Trans. AIME, 192 (1952), 214

24) K.-H. Ulrich, K. Bohnenkamp and H.-J. Engell: Arch. Eisenhüttenw., 36 (1965), 611.

25) O. Kubaschewski and B. E. Hopkins: Oxidation of Metals and Alloys, 2nd Ed., Butterworths, London, (1967).

26) H. K. Kohl and H.-J. Engell: Arch. Eisenhüttenw., 34 (1963), 411 .

27) E. Riecke, K. Bohnenkamp and H.-J. Engell: Arch. Eisenhüttenw., 38 (1967), 249.

28) W. Pluschkell and H. Yoshikoshi: Arch. Eisenhüttenw., 41 (1970), 715.

29) M. Sasabe, K. Goto and M. Someno: Trans. ISIJ, 10 (1970), 25. 